\title{
Epidemic Situation in Ukraine Related to the Quality of Drinking Water
}

\section{Iryna Rudenko*}

Department of European Integration of the State Sanitary Epidemiological Service of Ukraine, State sanitary and epidemiological service of Ukraine, Kiev, Ukraine

\section{Introduction}

The World Health Organization (WHO) puts a great emphasis on the study of diseases related to using or consuming poor-quality water and the absence of proper hygiene. Unfortunately, consumption of poor-quality water causes certain diseases in Ukraine.

\section{Methods}

The data of the official reports for 1997-2014 were used as the information basis for our study. We used theoretical and statistical methods of analysis. The purpose of the study was to obtain summary data regarding the outbreaks that occurred as a result of water consumption, to evaluate their scope, and the main causes of disease.

\section{Results}

70 outbreaks of severe enteric infections were registered among the population in 19 administrative territories in Ukraine over the past 17 years. The source of infection was poor-quality water. A total of 8265 people acquired an infection, 4140 of them were children.

Clinical manifestations of disease in the outbreaks can be divided into: viral hepatitis - 33 outbreaks (2947 people infected), dysentery - 18 outbreaks (1217 people infected), typhoid - 9 outbreaks (189 people infected), enteroviruses -4 outbreaks (457 people infected), rotaviruses -3 outbreaks (3353 people infected), opportunistic pathogenic microflora -2 outbreaks (70 people infected) and yersiniosis -1 outbreak ( 32 people infected).

Most patients (80\%) had clinical manifestations of gastroenteritis of rotavirus etiology. It was verified by clinical and viral data. The age group of the disease included children of 1-6 years old (60\% specific gravity).

The largest number of sick persons was registered in 2001during the outbreak of rotavirus infection in Odesa. 3143 people were infected, 2277of them were children.

\section{Conclusions}

Most outbreaks were related to the piped water contaminated by rotaviruses, as a result of emergencies in the water supply and sanitation systems.

The poor condition of the water supply in Ukraine is caused by the following factors: contamination of water supply reservoirs by untreated sewage; non-observance or absence of sanitary control zones of the water supply reservoirs; usage of old and ineffective techniques for water purification and decontamination; poor technical conditions of water supply plants and systems; and cutting-off water supply plants from the power supply system. The absence of the power for a long time allows bacterial contamination of the water in water supply systems.

\section{Keywords}

quality of drinking water; infectious disease; outbreak

\section{*Iryna Rudenko}

E-mail:dok7tor@ukr.net

ISDS Annual Conference Proceedings 2015. This is an Open Access article distributed under the terms of the Creative Commons AttributionNoncommercial 3.0 Unported License (http://creativecommons.org/licenses/by-nc/3.0/), permitting all non-commercial use, distribution, and reproduction in any medium, provided the original work is properly cited. 